\title{
Application of hot forming quenching on patchwork blank using two-stage refilled friction stir spot welding
}

\author{
D.S. Jo ${ }^{1}$, J.H. $\mathrm{Kim}^{1}$, D.C. $\mathrm{Ko}^{2}$, and B.M. $\mathrm{Kim}^{3, *}$ \\ ${ }^{1}$ Division of Precision and Manufacturing System, Pusan Nat'l Univ., Geumjeong-gu, Busan, South \\ Korea, 609-735 \\ ${ }^{2}$ Department of Convergence Science, Pusan Nat'1 Univ., Geumgeong-gu, Busan, South Korea, 609- \\ 735 \\ ${ }^{3}$ School of Mechanical Engineering, Pusan Nat'l Univ., Geumgeong-gu, Busan, South Korea, 609- \\ 735
}

\begin{abstract}
The purpose of this study is to apply Hot Forming Quenching (HFQ) on Patchwork Blank of AA6061 using Two-stage refilled Friction Stir Spot Welding (TFSSW). TFSSW is a developed joining method to improve joint strength of conventional Friction Stir Spot Welding (FSSW) and it consists of two stages. The first stage is a conventional FSSW process and second stage is a refilling process for refilling keyhole. The Design of Experiment (DOE) was used to optimize the TFSSW process parameters. A hat shape forming test was performed using a patchwork blank manufactured with the optimal process parameters to investigate validity of applying HFQ. Formed hat shape part was sequentially heat treated with artificial aging (T6) condition. The hardness of the weld zone was measured to confirm a drop of mechanical property in comparison with the conventional cold forming, which shows the validity of HFQ application to patchwork blank using TFSSW.
\end{abstract}

\section{Introduction}

In the recent years, aluminum alloy has been widely used in automotive industries to achieve higher fuel efficiency and improve crashworthiness. Also, Patchwork blank is adopted to manufacture automotive parts to maximize weight lightening: (1)However, there are several difficulties to improve patchwork blanks particularly for aluminum alloys. Because of their less familiar weldability requirements associated with conventional welding methods such as laser welding and resistance welding; (2)Therefore, in this study, Two-stage refilled Friction Stir Spot Welding(TFSSW) is used instead of the conventional welding method. Fig.1 shows the process flow of FSSW and TFSSW. TFSSW is a developed joining method to improve joint strength of conventional FSSW process and it consists of two stages; (3)TFSSW and FSSW is a solid state welding process that is

*Corresponding author: bmkim@pusan.ac.kr 
convenient for welding of aluminium alloys. FSSW has various advantages of low cost and low energy compared with the conventional welding method. Furthermore, recent studies on FSSW have been actively conducted. Effect of welding parameters on mechanical performance and microstructure of welded specimens(4-6), optimization of FSSW process parameters $(7,8)$ and effect of tool geometry on joint strength(9-11) were investigated.

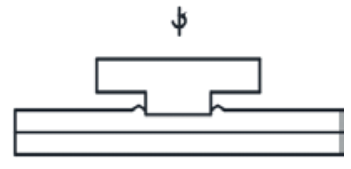

(a)

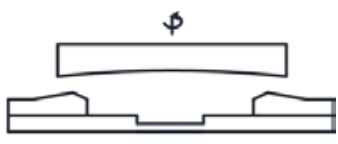

(d)

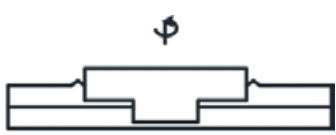

(b)

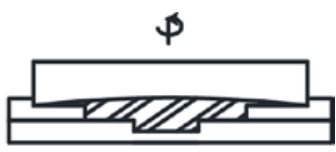

(e)

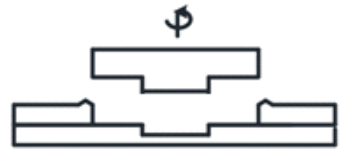

(c)

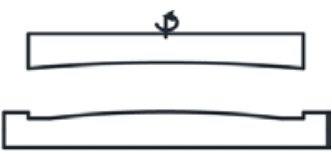

(f)

Fig. 1. Two-stage refilled Friction Stir Spot Welding process (a)-(c) first stage(conventional FSSW process), (d)-(f) second stage(TFSSW refilling process).

However, there is no study on forming of patchwork blank applying FSSW and TFSSW yet. Therefore, this study applied the forming of patchwork blank with Hot Forming Quenching(HFQ) using FSSW and TFSSW. The process flow is a step of forming the welded patchwork blank by heating it in a furnace, followed by press forming. HFQ is a process of hot forming a plate heated to a solution treatment temperature quenching it by a cooling channel provided in the die, and simultaneously performing hot forming and quenching(12-13).

In this study, a hat shape forming test was performed using a patchwork blank manufactured with the optimal TFSSW process parameters obtained by Design Of Experiment(DOE) to investigate validity of applying HFQ. Formed hat shape part was sequentially heat treated with artificial aging (T6) condition. The hardness of weld zone was measured to confirm drop of mechanical property in comparison with the conventional forming method, which shows the validity of HFQ application to patchwork blank using TFSSW.

\section{Optimization of TFSSW process parameters}

In order to manufacture patchwork blank using TFSSW, TFSSW process parameters and tool were selected. Many studies conducted on the optimization of FSSW process parameters. Based on previous studies, the TFSSW process parameters were selected as the tool rotational speed, plunge depth and dwell time, which have the greatest influence on joint strength. According to previous study (3), the tool of TFSSW 1stage(conventional FSSW) tool has pin diameter of $3 \mathrm{~mm}$, height of $1 \mathrm{~mm}$ and shoulder diameter of $10 \mathrm{~mm}$, concaveness of $3^{\circ}$, 2stage(refilling process)tool has no pin, $15 \mathrm{~mm}$ of shoulder diameter and concaveness of $5^{\circ}$ as shown in Fig.2. 

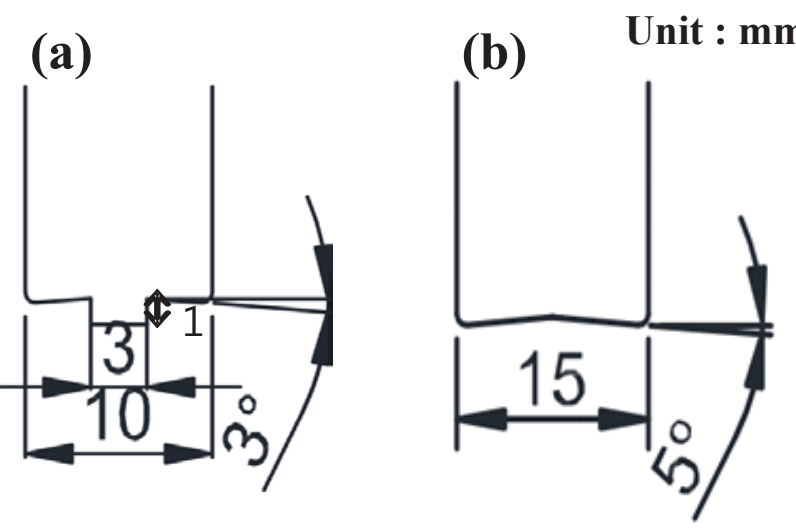

Fig. 2. (a) TFSSW 1stage tool (b) TFSSW 2stage tool.

The Patchwork blank was manufactured with AA6061-T6 (1.2t, 1.5t) and the process parameters of TFSSW and FSSW were optimized to best joint strength using the Taguchi method, one of the DOE. All experiments were carried out using a Friction Stir Process Machine Seeing Fig.3.

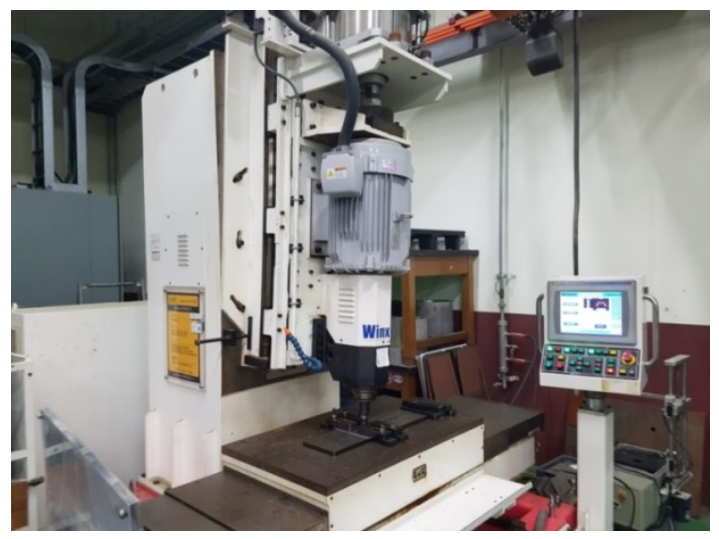

Fig. 3. Friction Stir Process Machine.

All specimens were welded by friction stir welding using fixtures. Lap shear test was carried out to evaluate the joint strength and it performed on a MTS machine. Fig. 4 shows the appearance of a typical lap shear test specimen after TFSSW process. In order to perform TFSSW process parameters optimization, the L9 orthogonal array table was prepared and lap shear test was performed accordingly. The influence of each process parameter on the maximum shear force was evaluated using the Taguchi method, one of the Design Of Experiment, and the average values at each level of process parameters are the main effect plot. In first stage, Taguchi method results showed that tool rotational speed is the most significant factor with a percentage contribution of $44.57 \%$ followed by plunge depth and dwell time with a contribution of $13.88 \%$ and $9.04 \%$ respectively. In second stage, Taguchi method results showed that plunge depth is the most significant factor with a percentage contribution of $44.57 \%$ followed by tool rotational speed and dwell time with a contribution of $13.88 \%$ and $9.04 \%$ respectively. In addition, the optimal levels of the rotational speed, dwell time and plunge depth were found to be $1400 \mathrm{rpm}, 8$ seconds and $2.6 \mathrm{~mm}$ in first stage and 1400rpm, 4seconds and $0 \mathrm{~mm}$ in second stage. 


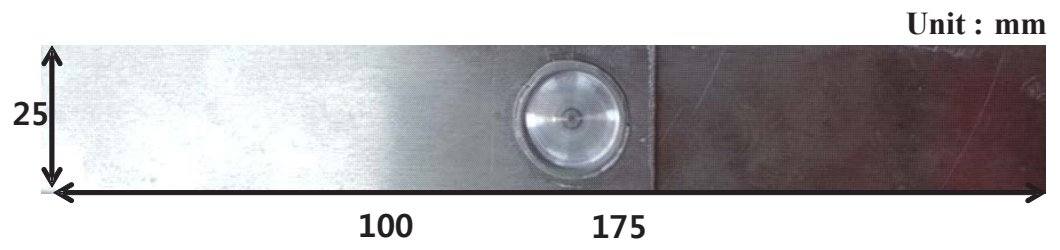

Fig. 4. appearance of a typical lap shear test specimen.

\section{Application of hot forming quenching}

\subsection{Experimental procedure}

A hat shape forming test was performed using a patchwork blank manufactured with the optimal process parameters. Fig.5 showed a patchwork blank with a $300 \mathrm{~mm} \times 260 \mathrm{~mm}$ AA6061-T6 1.5mm thickness and a 150mm $\times 120 \mathrm{~mm}$ AA6061-T6 1.2mm thickness with 9 spot weld points. The tools consisted of punch, pad and die. A total of 21 cooling channels were used to overcome the non-uniformly distributed temperature of the tools and cooling water constantly flowed through the channels to cool the tools during hot forming quenching. Next, the patchwork blank heated at the solution temperature for 15 minutes is transferred to the hat type die and press formed. During Forming, the punch speed was fixed at $20 \mathrm{~mm} / \mathrm{s}$ and the holding force were $48000 \mathrm{~N}$, respectively. In addition, due to the cooling channel in the die, quenching was performed simultaneously with forming and for sufficient quenching time, a quenching time of 10 seconds was given after forming. Subsequently artificial aging (T6 condition) was performed. Fig. 6 showed the state of patchwork blank after hat shape forming.

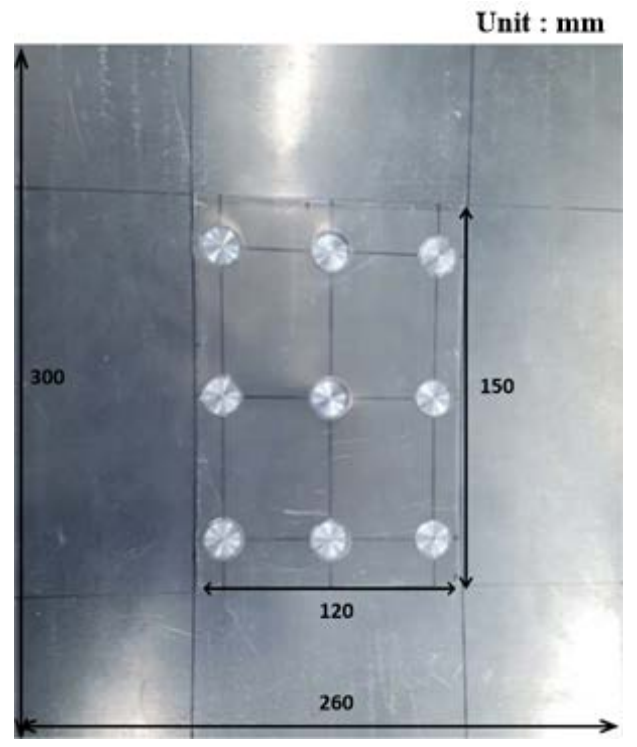

Fig. 5. Appearance of patchwork blank using TFSSW. 


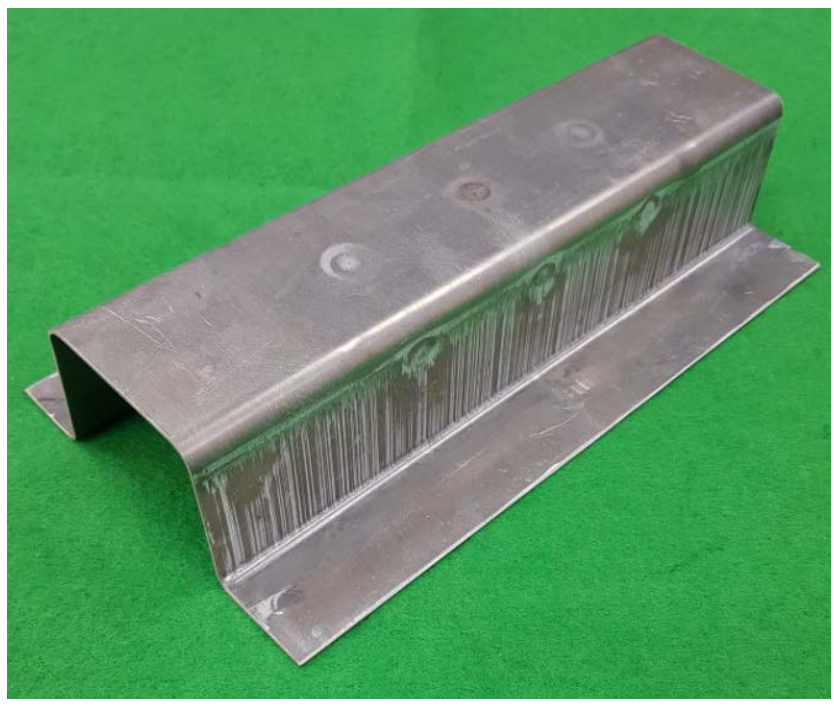

Fig. 6. Appearance of formed hat shape.

\subsection{Measurement of weld zone hardness}

The hardness of the weld zone before and after the forming was measured to confirm that a drop of the hardness of the weld zone, which is one of the disadvantages of the TFSSW.

Formed hat shape part was heat treated with artificial aging (T6) condition. Sequentially after cutting the hat shaped part, the hardness from the center of the weld zone to $12 \mathrm{~mm}$ was measured at intervals of $2 \mathrm{~mm}$. The results of Vicker's hardness measurements are shown in Fig. 8 as the average hardness of the left, center, and right. It can be confirmed that the hardness is restored when hot forming quenching is applied.

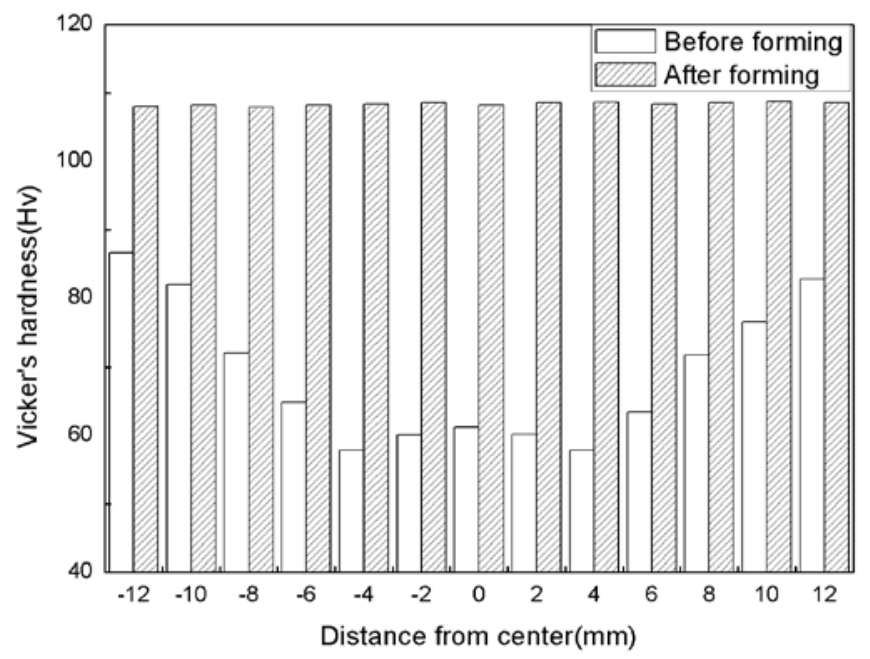

Fig. 8. Result of hardness measurement. 


\section{Conclusions}

The objective of this study is to apply hot forming quenching on patchwork blank using TFSSW. Using the Taguchi method, one of the design of method, the optimal process parameters with the best joint strength were selected. Rotational speed, dwell time and plunge depth were found to be $1400 \mathrm{rpm}$, 8seconds and $2.6 \mathrm{~mm}$ in first stage(conventional FSSW) and 1400rpm, 4seconds and $0 \mathrm{~mm}$ in second stage(refilling process). Also, a hat shape forming test was performed using a patchwork blank manufactured with the optimal process parameters. As a result of forming, forming was performed without defect. Formed hat shape part was heat treated with artificial aging(T6) condition. The hardness of weld zone before hot forming quenching is average $70 \mathrm{Hv}$ and after hot forming quenching is average $110 \mathrm{Hv}$, respectively. It can be seen that the hardness of the material recovered.

\section{Acknowledgment}

This work was supported by the National Research Foundation of Korea(NRF) grant funded by the Korea government(MSIP) (No. 2012R1A5A1048294).

\section{References}

1. M. Merklein, M. Johannes, M. Lechner and A. Kuppert, J. Mater. Process. Technol., A Review on Tailored Blanks-Production, Applications and Evaluation, 214, 151-164 (2014)

2. M. C. Stasik, R.H. Wagoner, Int. J. Form. Process. Forming of tailor-welded aluminum blanks, 1, 9-34 (1998)

3. M. Sajed, J. Manuf., Processes, Parametric study of two-stage refilled friction stir spot welding, 24, 307-317 (2016)

4. Z. Shen, X.Yang, S.Yang, Z. Zhang, Y.Y. In, Mater Des, Microstructure and mechanical properties of friction spot welded 6061-T4 aluminum alloy, 54, 766-778 (2014)

5. Z. Zhang, X. Yang, J. Zhang, G. Zhou, X. Xu, B. Zou, Mater Des, Effect of welding parameters on microstructure and mechanical properties of friction stir spot welded 5052 aluminum alloy, 32, 4461-4470 (2011)

6. H. Bisadi, M. Sajed, S. Sattari, The 5th National Conference of Metals and Materials Forming, Effect of welding parameters on mechanical properties of friction stir spot welded aluminum alloys (2011)

7. M. Tutar, H. Aydin, C. Yuce, N. Yavuz, A. Bayram, Mater Des, The optimization of process parameters for friction stir spot-welded AA3003-H12 aluminum alloy using a Taguchi orthogonal array, 789-797 (2014)

8. Y. Bozkurt, M. K. Bilici, Mater Des, Application of Taguchi approach to optimize of FSSW parameters on joint properties of dissimilar AA2024-T3 and AA5754-H22 aluminum alloys, 51, 513-521 (2013)

9. M. Sajed, M. Sedighpour, A. Rasouli, S. H. Daneshpour, The 1st National Conference of Applied Mechanics, An experimental study on effect of tool probe geometry on strength of friction stir spot welded aluminum sheets (2014)

10. H. Badarinarayan, Y. Shi, X. Li, K. Okamoto, Int J Mach Tools Manuf, Effect of tool geometry on hook formation and static strength of friction stir spot welded aluminum 5754-O Sheets 49, 814-823 (2009)

11. Y. Tozaki, Y. Uematsu, K. Tokaji, Int J Mach Tools Manuf, Effect of tool geometry on microstructure and static strength in friction stir spot welded aluminum alloys, 47, 
2230-2236 (2007)

12. X.B. Fan, Z.B. He, S.J. Yuan, P. Lin, Mater. Sci. Eng., Investigation on Strengthening of 6 A02 Aluminum Alloy Sheet in Hot Forming-quenching Integrated Process with Warm Forming-dies, 587, 221-227 (2013)

13. D.H. Ko, J.H. Kim, C.J. Lee, D.C. Ko, B.M. Kim, Trans. Kor. Mech. Eng, Evaluation of Formability and Mechanical Characteristic for Hot Forming Quenching in Sheet Forming of Al6061 Alloy, 37, 483-490 (2013)

14. B.C. Shang, Z.M. Yin, G. Wang, B. Liu, Z.Q. Huang, Mater. Des., Investigation of Quench Sensitivity and Transformation Kinetics during Isothermal Treatment in 6082 Aluminum Alloy, 32, 3818-3822 (2011) 